\title{
An unusual aetiology of back pain
}

\author{
Wasim Al Assad, Alejandro Marinos
}

Internal Medicine Department, Oakland University William Beaumont Hospital, Royal Oak, Michigan, USA

\section{Correspondence to} Dr Wasim Al Assad, wasim. alassad@beaumont.edu

Accepted 22 May 2015

\section{SUMMARY}

We present the case of a healthy young man who developed pyogenic myositis, an infection that is rare in the USA. He had no prior medical conditions except for an obsessive-compulsive disorder and skin picking disorder resulting in multiple superficial skin infections. He presented to our hospital with acute back pain. He was found to be septic with fever, tachycardia and elevated white cell counts. Imaging revealed evidence of myositis in the gluteal region. He was treated with antibiotics and fully recovered. It is likely that the skin picking disorder and the recurrent superficial skin infections are responsible for the development of this infection.

\section{BACKGROUND}

Pyogenic myositis is an uncommon disease in the USA; it can lead to sepsis and death. We hope to illustrate some of the clinical characteristics of this illness and enrich the differential diagnosis of our colleagues.

\section{CASE PRESENTATION}

A 31-year-old man was seen in the emergency department at our tertiary medical centre with symptoms of lower back pain of a few days duration following recent strenuous activity. The patient described the location to be in the lower back towards the left gluteal region, rated the intensity to be 'excruciating', and mentioned radiation to the left hip and knee. His pain worsened with movement. Although he denied any saddle anaesthesia, bladder dysfunction, sciatica or weakness, he reported fever, night sweats, poor appetite and a few episodes of nausea and vomiting in the hours preceding his arrival. His medical history revealed obsessive-compulsive disorder and possible skin picking disorder, resulting in multiple superficial skin infections. On his social history, he reported daily cigarette smoking, and occasional marijuana and cocaine use. He denied any intravenous drug use. He was in a monogamous relationship and was not on any regular medications.

On physical examination, his vital signs showed a blood pressure of $128 / 77 \mathrm{~mm} \mathrm{Hg}$, heart rate of $151 \mathrm{bpm}$ and temperature spikes of $38^{\circ} \mathrm{C}$. On inspection of his lower back, there were no visible skin abnormalities except for a single boil in the upper third of his lateral left thigh. We also found multiple $0.2-0.5 \mathrm{~cm}$ skin boils on the face, chest and upper back. The lesions did not exhibit surrounding erythaema or drainage. On palpation of the lower back area, he experienced an exquisite tenderness. Otherwise, his physical examination was unremarkable except for tachycardia.

\section{INVESTIGATIONS}

Laboratory work revealed a white cell count of 23.6, as shown in table 1. CT showed diffuse enlargement of the left gluteus medius and minimus with diffuse oedema between the muscle layers and fluid overlying the greater trochanter, consistent with myositis (figure 1A). MRI showed diffuse oedema in multiple muscles including the left gluteus medius, gluteus maximus, tensor fasciae latae, portions of hip adductors and proximal vastus lateralis, in addition to fluid along the myofascial planes of the posterior and anterior compartment of the proximal left thigh. It also showed a focal area of T2 hyperintensity in the myotendinous junction of the left gluteus medius, measuring $17 \mathrm{~mm} \times 8 \mathrm{~mm}$ (figure $1 \mathrm{~B}, \mathrm{C}$ ).

Blood cultures grew methicillin-resistant Staphylococcus aureus.

\section{TREATMENT}

The patient was initially treated with broadspectrum antibiotics in addition to aggressive fluid therapy. Antibiotics were deescalated to vancomycin once blood culture results became available. Transoesophageal echocardiogram showed no endocardial involvement, while subsequent blood cultures were negative.

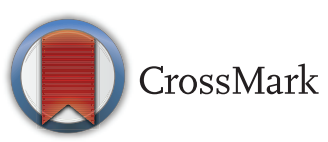

To cite: Al Assad W Marinos A. BMJ Case Rep Published online: [please include Day Month Year] doi:10.1136/bcr-2015209489
Table 1 Initial values for selected tests from the patient's blood counts and metabolic panel

\begin{tabular}{lclr}
\hline Test & Result (range) & Test & Result (range) \\
\hline White cell count & $23.6(3.5-10.1)$ & C reactive protein & $36.5(0.0-0.8)$ \\
Haemoglobin & $13.5(13.5-17)$ & ESR & $44(0-15)$ \\
Neutrophils & $19.6(1.6-7.2)$ & Creatinine & $1.5(0.6-1.4)$ \\
Lymphocytes & $1.8(1.1-4.0)$ & Blood urea nitrogen & $17(8-22)$ \\
Immature granulocytes & $0.23(0.0-0.04)$ & Creatine kinase & $874(40-230)$ \\
Platelets & $214(150-400)$ & &
\end{tabular}

ESR, erythrocyte sedimentation rate. 

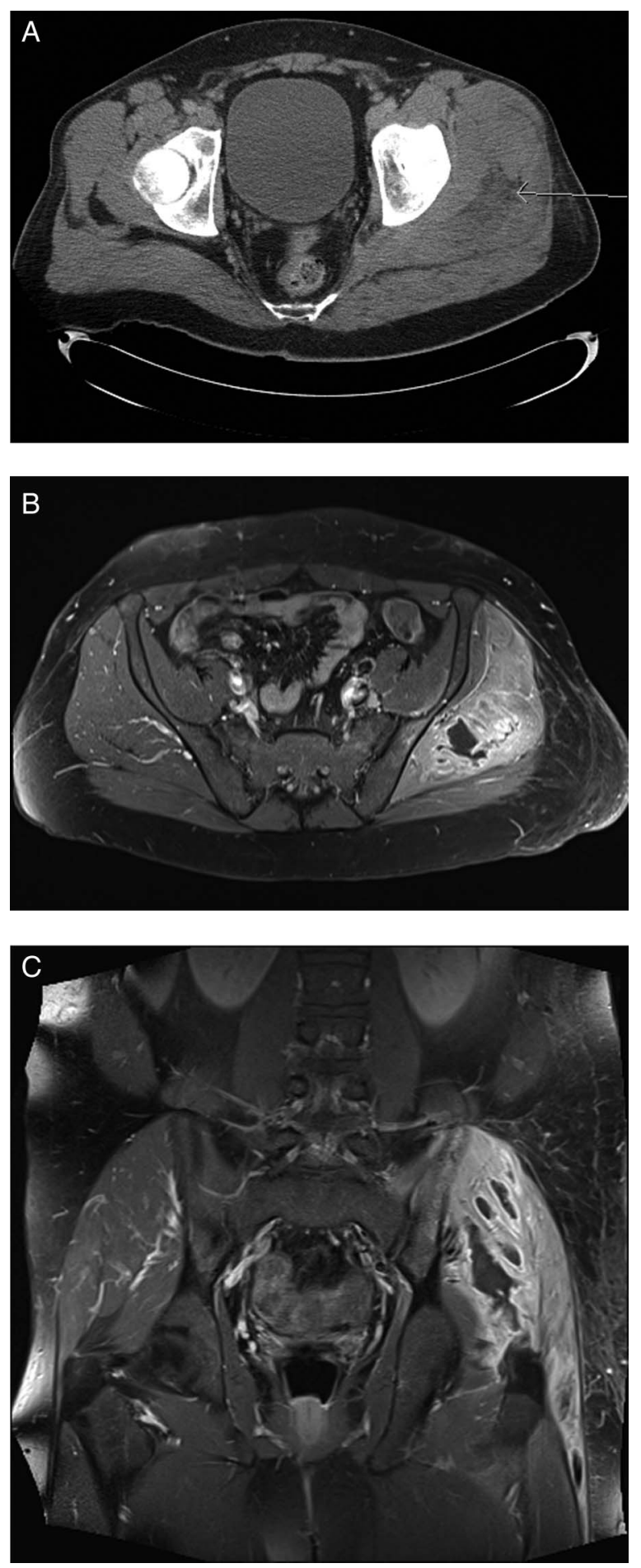

Figure 1 (A) CT abdomen and pelvis shows diffuse enlargement of the left gluteus medius and minimus with diffuse oedema between the muscle layers and fluid overlying the greater trochanter. (B and C) MRI of the pelvis shows extensive oedema throughout the left gluteus medius and extending to the left piriformis muscle with multiple fluid collections.

\section{OUTCOME AND FOLLOW-UP}

The patient had a gradual improvement with stabilisation of his vital signs and slow normalisation of white cell counts. His pain improved gradually. He finished a 6-week course of intravenous vancomycin and fully recovered. On discharge, he was asked to establish care with a general practitioner at our medical centre for further management of his chronic issues.

\section{DISCUSSION}

Pyogenic myositis is a primary deep bacterial infection of the skeletal muscle. While this pathology is exceedingly rare in the United States, as illustrated by reports of only about 330 cases from 1981 to 2002 in this country, it is more common in tropical regions. ${ }^{1}$ The physiopathology of pyomyositis is thought to be secondary to transient bacteraemia. ${ }^{2}$ Likely, the bacteraemia in our patient originated from superficial skin infections. While pyomyositis has subacute development and progression in three distinctive stages over 2 or 3 weeks, it presents acutely in rare instances. S. aureus accounts for $95 \%$ of cases of pyomyositis in tropical areas, but it only represents $66-70 \%$ of cases in temperate areas. $^{2}$ A proportion (20-50\%) of the patients with pyogenic myositis refer to recent trauma, vigorous exercise or a local primary dermatological process. ${ }^{1}$ Major predisposing factors for pyomyositis include intravenous drug abuse, HIV, diabetes mellitus, haematological, and immunological or rheumatological conditions. $^{12}$

\section{Learning points}

- Pyogenic myositis is a rare condition in the USA.

- Deep tissue infections should be suspected in patients who present with a septic condition without a clear source of infection.

- Superficial skin infections might be a risk factor for transient bacteraemia and pyogenic myositis.

Competing interests None declared.

Patient consent Obtained.

Provenance and peer review Not commissioned; externally peer reviewed.

\section{REFERENCES}

1 Crum NF. Bacterial pyomyositis in the United States. Am J Med 2004;117:420-8.

2 Mandell GL, Bennett JE, Dolin R. Mandell, Douglas, and Bennett's principles and practice of infectious diseases. 7th edn. Philadelphia, PA: Churchill Livingstone/ Elsevier, 2010. 
Copyright 2016 BMJ Publishing Group. All rights reserved. For permission to reuse any of this content visit http://group.bmj.com/group/rights-licensing/permissions.

BMJ Case Report Fellows may re-use this article for personal use and teaching without any further permission.

Become a Fellow of BMJ Case Reports today and you can:

- Submit as many cases as you like

- Enjoy fast sympathetic peer review and rapid publication of accepted articles

- Access all the published articles

- Re-use any of the published material for personal use and teaching without further permission

For information on Institutional Fellowships contact consortiasales@bmjgroup.com

Visit casereports.bmj.com for more articles like this and to become a Fellow 